Studia UBB 四igitalia, Volume 65 (LXV) 2020, December, Issue 2, 21-30

Published Online: 2021-01-25

DOI: 10.24193/subbdigitalia.2020.2.02

\title{
The enlightened minds of the pastoral land of Mărginimea Sibiului
}

\author{
Teodora Maria Piț
}

\begin{abstract}
This project aims to configure a map of the most important personalities in the Mărginimea Sibiului. The present research presents practically the methodology of all the stages completed. Starting with the selection of information, its organization in tables and up to the geographical representation of the information gathered about intellectuals. The career path of each one is not a complex one, but the idea started from the fact that we wanted to demonstrate how a rural, agrarian area, restricted from a geographical point of view, offered to the national culture several paramount intellectuals such as loan Lupaș, Octavian Goga, Emil Cioran, Samuel Micu.
\end{abstract}

Keywords: digital humanities, Airtable, Qgis, database, maps, Google Maps, Transylvania

\section{Introduction}

The consequences of the digitalization of humanities are varied, but impactful nonetheless. Whether we are referring to how research is conducted or how people perceive data, it becomes apparent that the process of digitalization greatly increased accessibility to different sources of information. More than this, nowadays, a researcher who wants to achieve international recognition is almost obligated, to utilize interdisciplinary methods. Thus, digital humanities prompted the combined use of disciplines which, so far, have been regarded as being completely separate. The research at hand represents such an example. By merging history, geography, informatics and their specific work instruments we have created a map used to underline a certain geographical region in which numerous cultural personalities originate.

The present research brings to light technical and methodological aspects that can serve a historical-geographical research, but with more accents in the spatial, territorial field. The border of Sibiu is a less researched area, which is why it is worth focusing on its importance in the history of Romanian intellectuals. 
To fully understand the implications of the research at hand and why it became an object of study it is imperative to provide a short description of the region. The two points of view followed were: historical and geographical. The region's historical significance can be traced back to its traditions and the authentic Romanian nature of the area. Historical sources mention the first settlements in the early $13^{\text {th }}$ century (Cisnădie, Amnaș), followed by later ones in the $14^{\text {th }}-15^{\text {th }}$ centuries (Tălmaciu, Orlat, Săliște). People residing in this Transylvanian nook were able to maintain traditional Romanian customs despite the tumultuous Hungarian administration due to their main occupation: sheep shepherding. This allowed such people, known as "mocani" or "mărgineni", to maintain close ties to their brothers in Valahia/Walachia/Țara Românească, across the Carpathian Mountains.

Although it is a predominantly agricultural area, many of the shepherds here have supported their children in their education. Some of the descendants of the sheep shepherds became priests, teachers, educators, scholars, and even saints. This offers us a more profound understanding of the historical and geographical region known as Mărginimea Sibiului

Therefore, education in local schools proved to have a major impact on the life of the community previously described. Such an example is the school in Sălişte, first mentioned, in historical documents, in 1616 and towards the end of the $19^{\text {th }}$ century and the beginning of the $20^{\text {th }}$ century, there was an explosion of such institutions. Notable ones were two local branches/departments of ASTRA (The Transylvanian Association for Romanian Literature and the Culture of the Romanian People), the "Gathering of craftsmen" ( 1882) and the ", Gathering of firefighters" ( 1882). Apart from these, a number of literary societies can also be identified.

\section{Structure and research methods}

\section{Database}

The present research has three main pillars: a database constructed with Airtable, a geographical representation in QGis, and a map created with Google Maps. The copious information gathered was first introduced into the aforementioned database to facilitate its further usage. Thus, the key element of the research lies with Airtable. Firstly, it is important to establish clearly how Airtable operates. It can be defined as a cloud-based software company that blends a traditional spreadsheet with a database. Moreover, bases can be built from existing templates or they can also be built from scratch.

As a first step, we created a table in which the information was organized on rows and columns in the following order: Number, Name, Birthplace, Date of Birth, Death place, Date of Death, Professional Path, Highest-ranking occupation (Fig.1). 


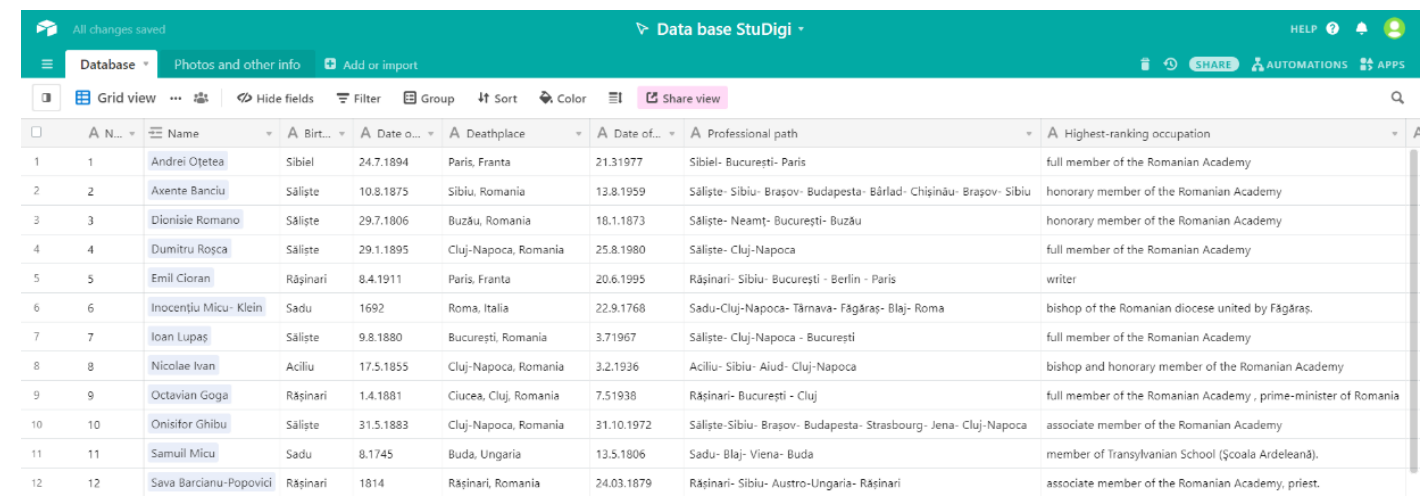

Fig. 1 Creating the main table

To increase the complexity of the table, we then created another table, containing mainly images and further links towards information/documents/webpages about each individual. They were grouped in columns in the following order: Name, Number, Photo, More Information. This was then linked to the first table that we created (Fig. 2).

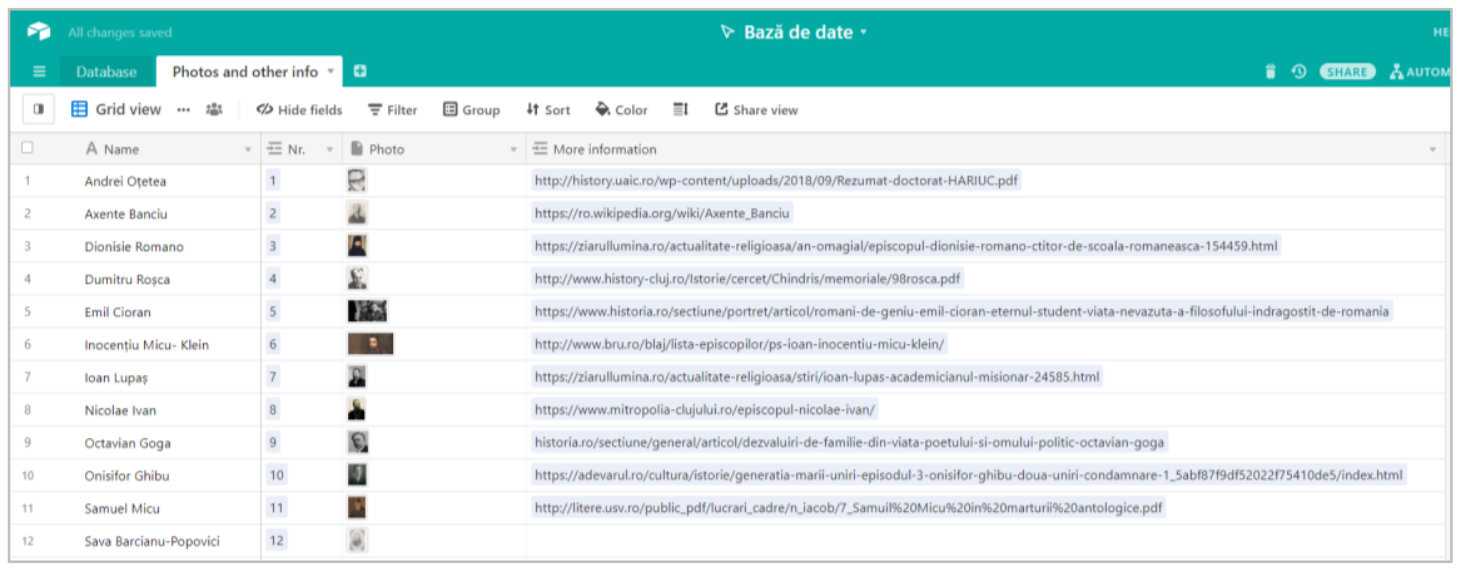

Fig. 2 Photos and other info Table

In order to facilitate the access to the different information types referring to a single individual, we created links between spreadsheets and records. (Fig. 3, Fig. 3.1).

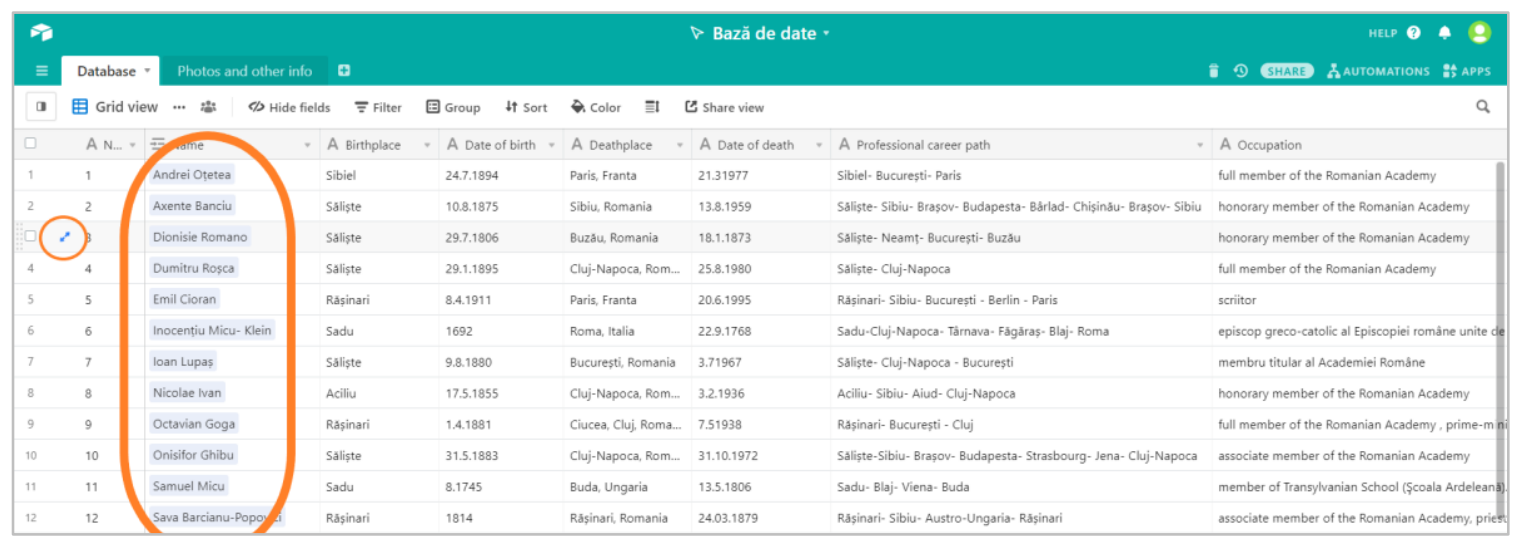

Fig. 3. Links between Name from spreadsheet Database and spreadsheet Photos and other info. 

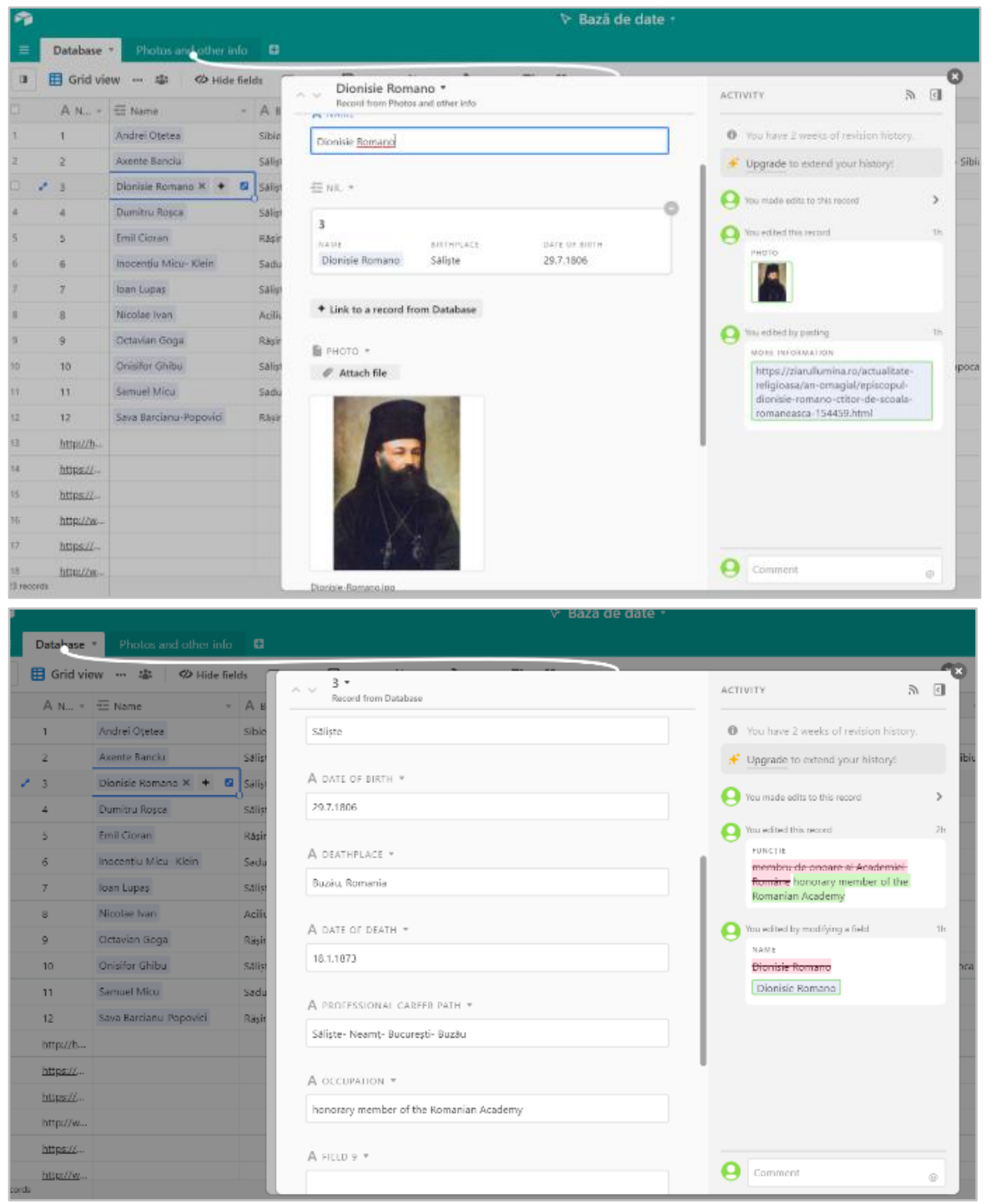

Fig. 3.1. Example

\section{Geospatial representation}

Just as with the construction of the database, to create a geospatial representation that was used in further steps, we relied on a particular tool: QGis. It can be defined as a collection of software that allows you to create, query, and analyse geospatial data. Geospatial data refers to information about the geographic location of an entity. This often involves the use of a geographic coordinate, like a latitudinal or longitudinal value. Spatial data is another commonly used term, as are: geographic data, GIS data, map data, location data, coordinate data, and spatial geometry data. To use it, we were required to install a new plug-in: Quick Map Services ( an easy basemap in Qgis).

In order to save the data imported into QGis, we had to create a new type of layer, called Shapefile. This is an Esri vector data storage format for storing the location, shape, and attributes of geographic features. It is stored as a set of related files and contains one feature class. (Fig.4) 


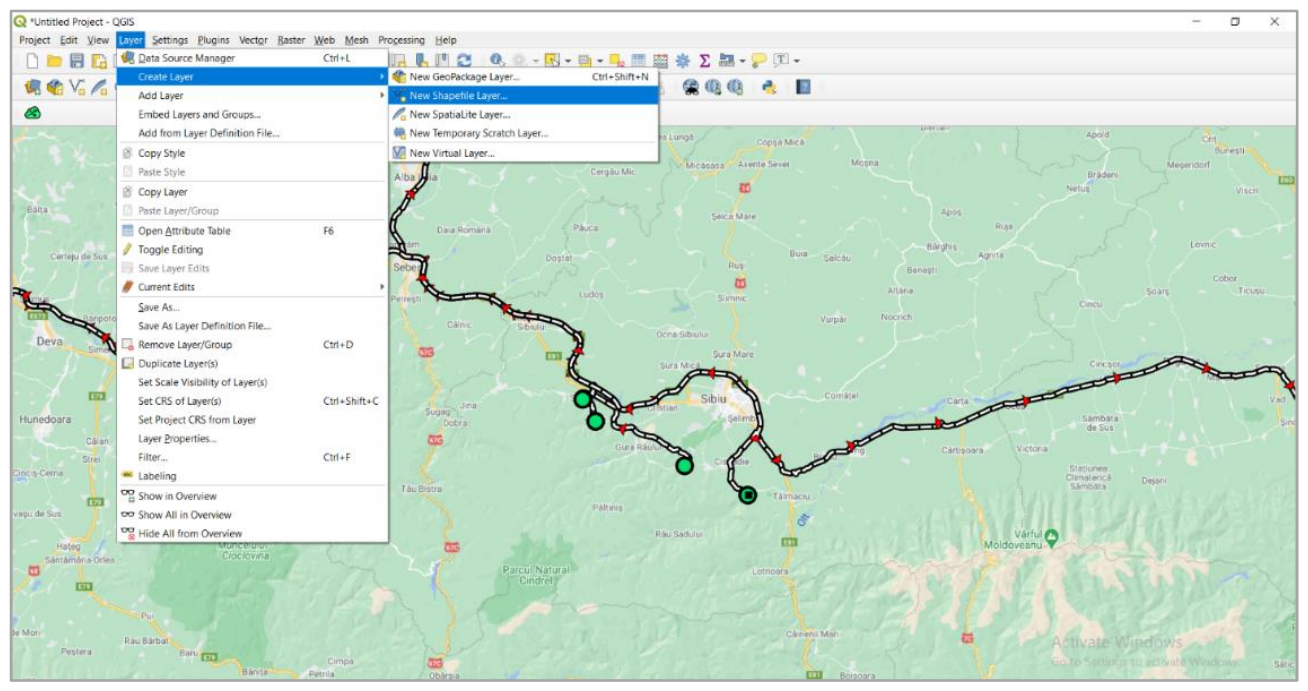

Fig. 4. Making the new Shapefile Layer. It was created based on minimal data such as number, birthplace, death place, occupation (Fig. 5)

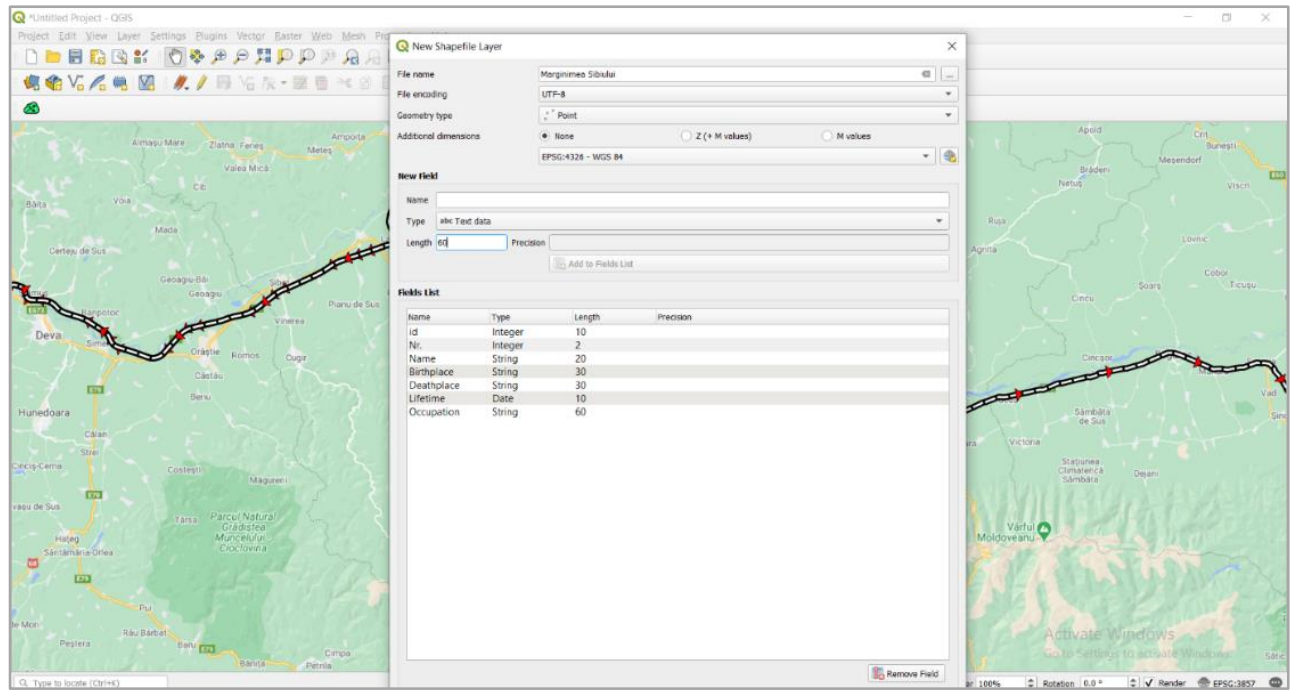

Fig.5. Creating new fields.

Marking the place on the map was possible with the use of the Add Point Feature function (Fig.6). This way, the exact spot was created on the map, furthermore requiring only the completion of the newly made table with information (Fig. 7). 


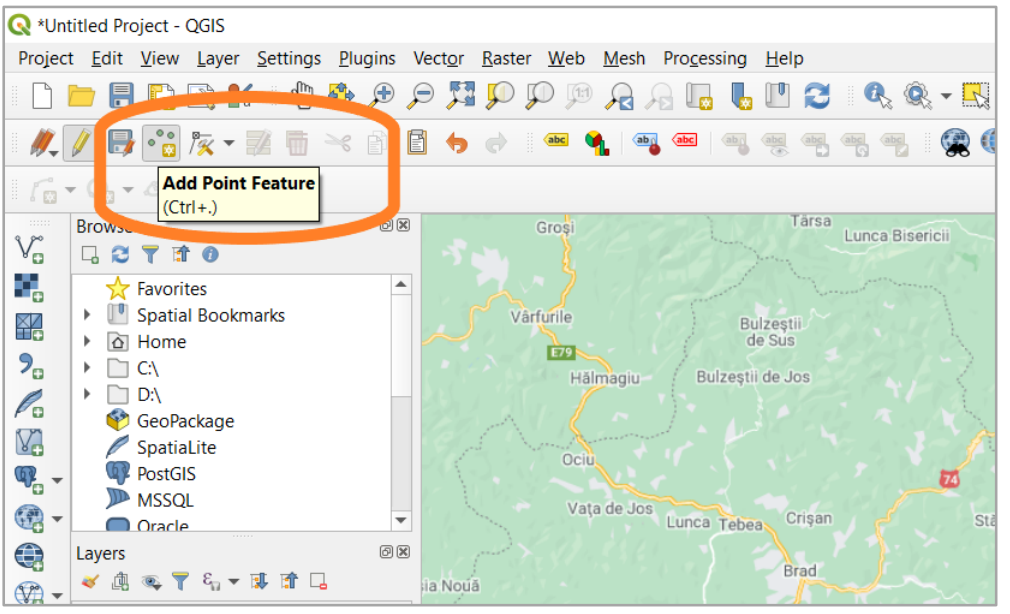

Fig.6. Add Point Feature function

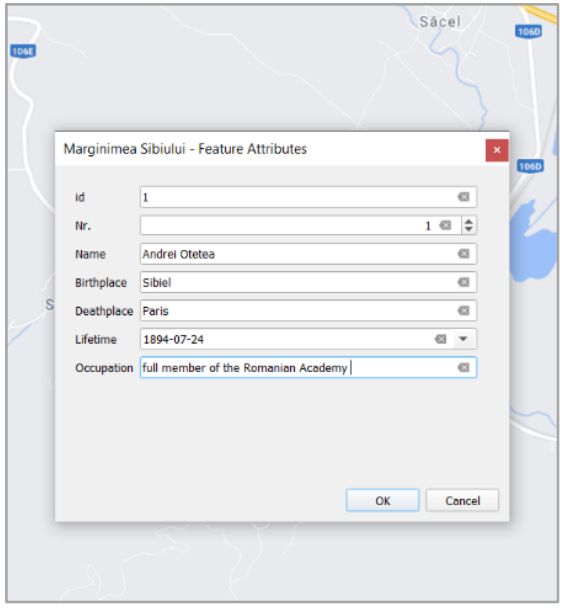

Fig. 7 Filling the table with data

Additionally, using the Add Polygon feature we were able to trace the territorial footprint of the area we named Mărginimea Sibiului. This stage was crucial due to the fact that it offered visibility to the discussed area. (Fig. 8)

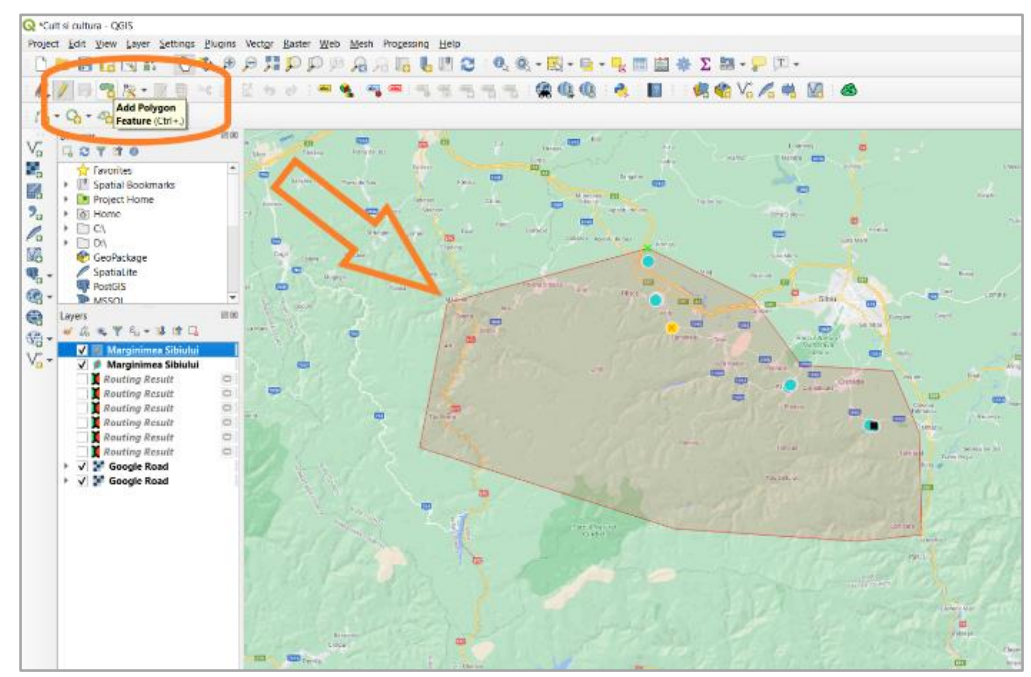

Fig. 8. The footprint of the area Mărginimea Sibiului

As a result of QGis offering a wide array of options concerning ways of personalizing maps and different elements, the next step included customizing some symbols using Layer Properties. We adjusted them using the categorized function with the value Birthplace. This way, individual from the same village was marked with a distinct colour (Fig. 9). 


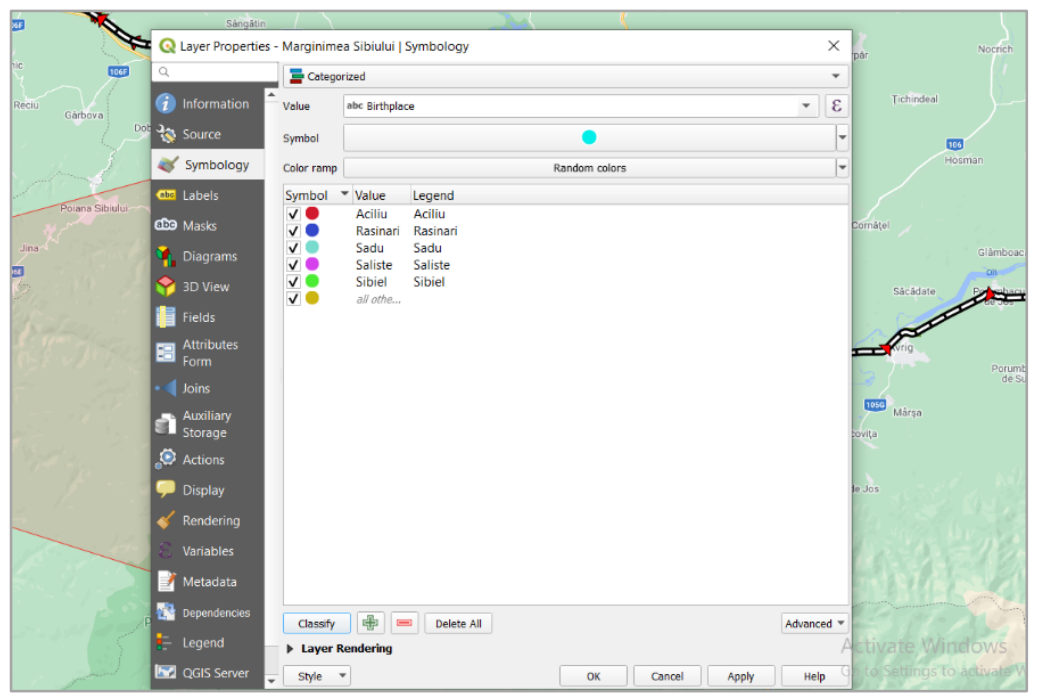

Fig. 9. Editing Layer Properties

The main reason that influenced us in choosing to work with Qgis is its Field Calculator function (Fig. 10). Using it we were able to calculate the latitude and longitude specific to each person of each place marked on the map. The points marked on the map are not precise locations, but they have been marked separately to differentiate one person from another. The numbers were generated automatically on two separate columns: $x \_l o n g$ and $x$ _lat (Fig. 11).

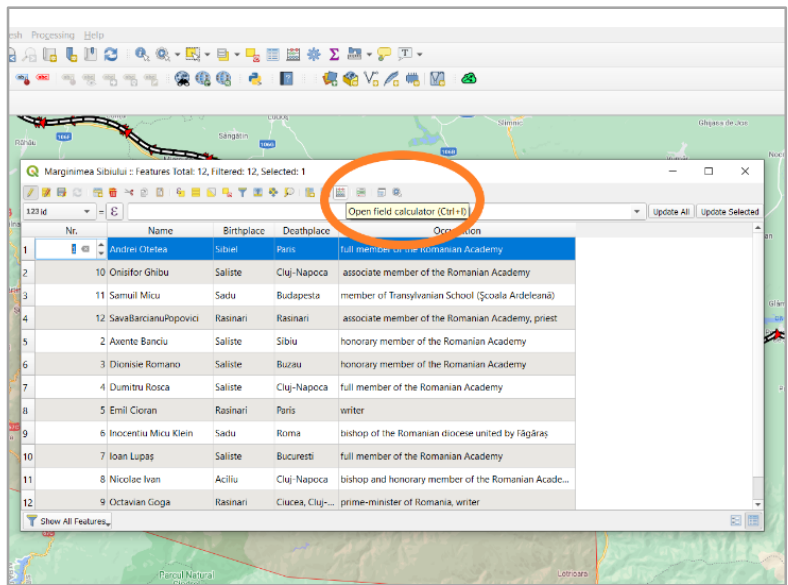

Fig. 10. Field Calculator

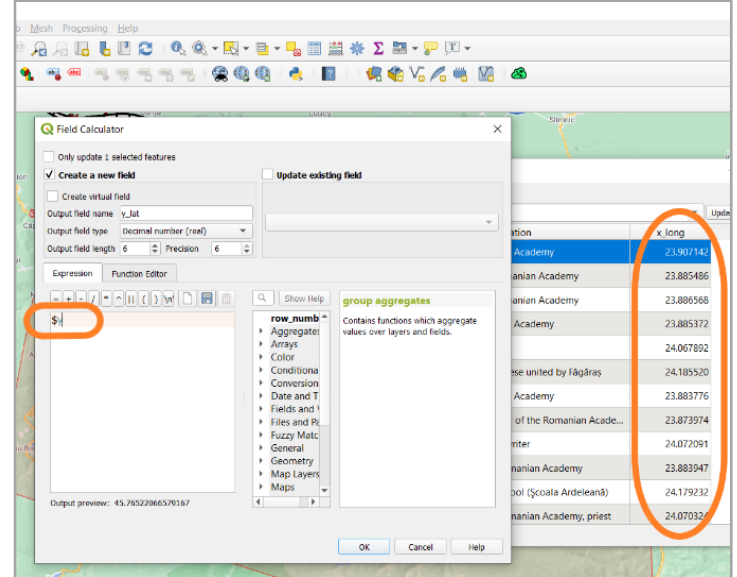

Fig. 11. Columns x_long și x_lat

With all the preparatory work finished, the final step in QGIS included exporting the content created in a compatible format to the Google Maps program. We are referring to a .CSV type of document (Fig. 12). Thus, we accessed Google Maps using Google Drive, where we had the possibility of creating a new map by importing the table saved in QGIS (Fig. 13). 


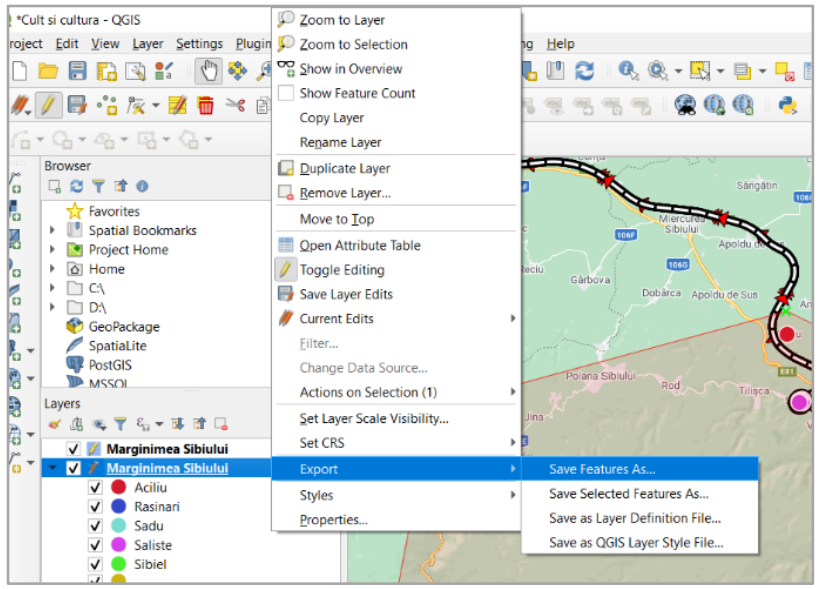

Fig. 12. Save Features As .CSV File.

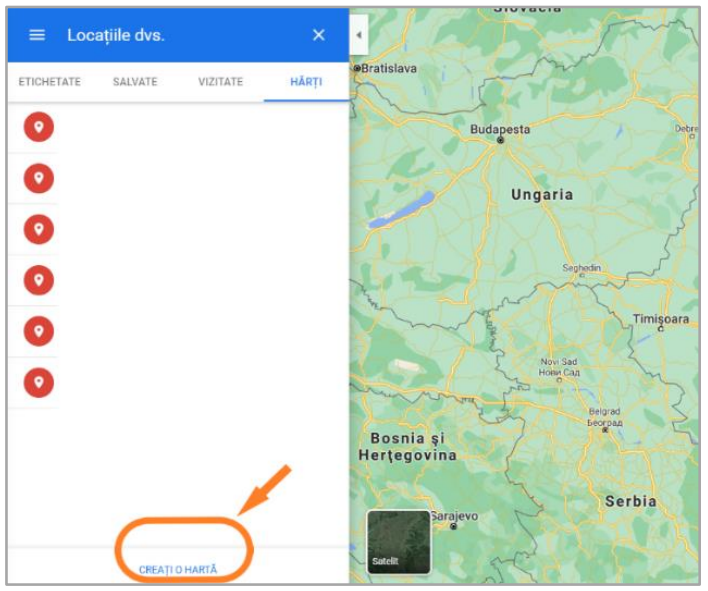

Fig. 13. Create a Map

The new map was named accordingly: The enlightened minds of the pastoral land of Mărginimea Sibiului. Its reference points were the coordinates calculated in QGIS and the markings were named after the data included in the Name column. Thus, analyzing the example of fig.14 illustrates the fact that the data gathered with the help of Airtable (organised in QGis and then transposed to GoogleMaps) created an interactive map. A person accessing it can see much more than a simple map, each location having embedded information regarding different individuals.

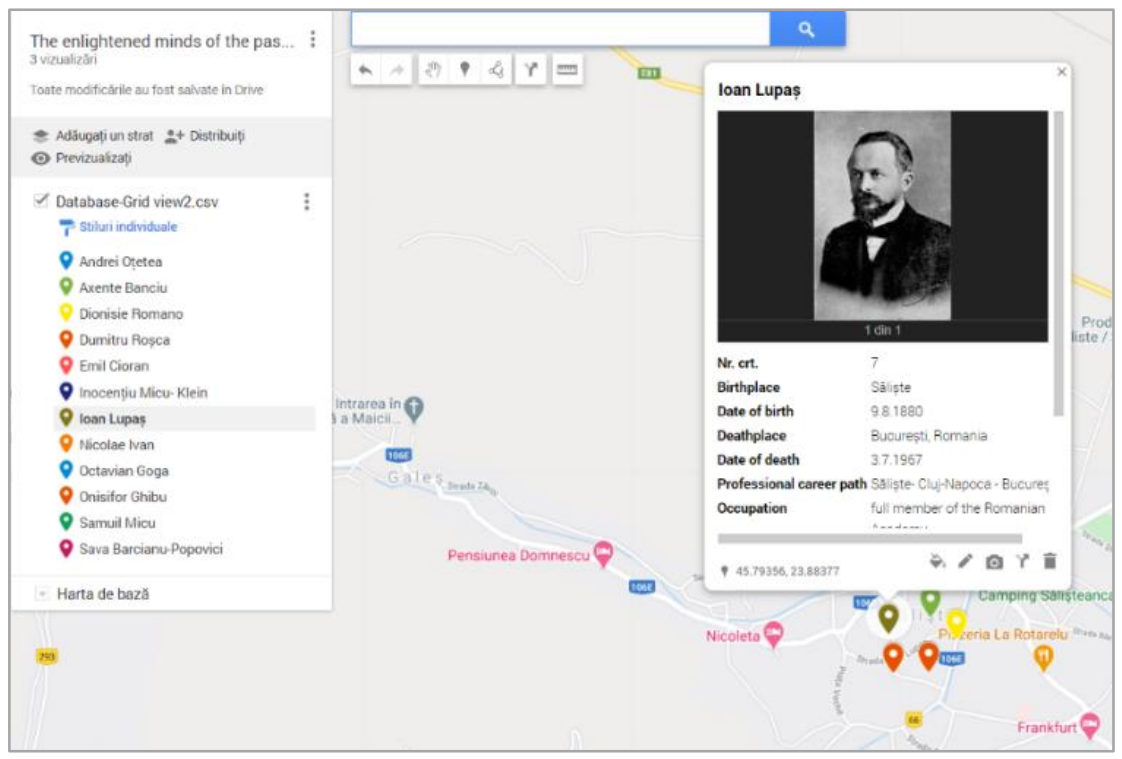

Fig. 14. Example

The final step of our procedure involved tracing a similar form to the geographical area of Mărginimea Sibiului, as shown in the example. This was necessary in order to better visualize it in Google My Maps. A similar step was done in QGIS. 


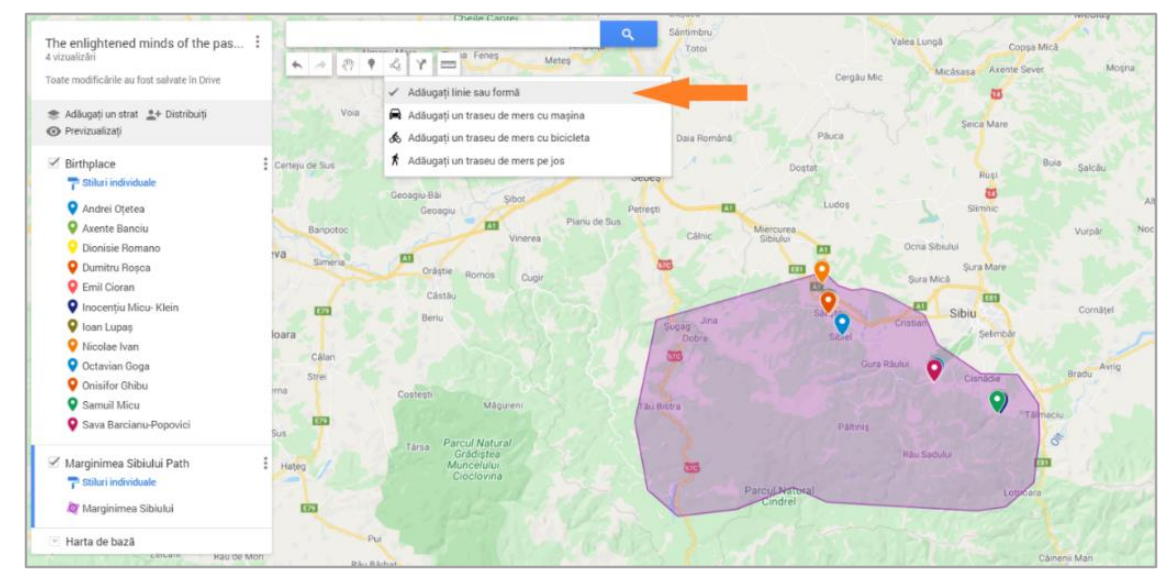

Fig. 15. The footprint of the area Mărginimea Sibiului

\section{Conclusions}

The steps taken and thoroughly presented in the previous lines had as a result the construction of a map suggestively titled "The enlightened minds of the pastoral land of Mărginimea Sibiului". This map wishes to bring forth, to the attention of the general population, a narrow, rural, and historical area from the heart of Transylvania. Its relevance becomes apparent once one takes into account the intellectuals that draw their origins from this area.

The research undertaken can be viewed as a stepping stone in the further development of similar projects that investigate the cursus honorum of Romanian intellectuals. More so, it is a useful tool in the development of tourism in the area due to the fact that through this map, those who will visit the Mărginimea Sibiului area, will know more about its importance considering the number of intellectuals here.

\section{Acknowledgments}

This research would not have been possible without the skills cultivated during the pilot-module regarding Digital Humanities, organised by the Star UBB Institute and Digi HUBB. With these lines, we would also like to bring thanks to scientific researcher Mrs. Rada Varga for organising and facilitating such ways of interdisciplinary learning.

The map can be seen by accessing the link: https://www.google.com/maps/d/u/0/edit?hl=ro\&mid=1XZluxSM0w3BWOROQXDKk147qABQgxhm\& $\|=45.69343169703502 \% 2 C 23.900137299999987 \& z=11$ 


\section{Bibliography:}

Cornel Irimie, Nicolae Dunăre, Paul Petrescu, Mărginenii Sibiului, Editura Științifică și Enciclopedică, București, 1985.

William Porter, ,,Airtable review: A drop-dead easy relational database management system",Software, Macworld, 24 February 2016, https://www.macworld.com/article/3036505/airtable-review-a-drop-dead-easyrelational-database-management-system.html. James Gray, „Getting Started With Quantum GIS”, Software, Linux Journal, 26 March 2008, https://www.linuxjournal.com/content/getting-started-quantum-gis 